\title{
RADAR DA INOVAÇÃO COMO FERRAMENTA PARA O ALCANCE DE VANTAGEM COMPETITIVA PARA MICRO E PEQUENAS EMPRESAS
}

\author{
Gustavo Dambiski Gomes de Carvalho \\ Mestre em Administração pela Pontifícia Universidade Católica do Paraná - PUCPR \\ gustavo.dambiski@gmail.com (Brasil)
}

\section{Wesley Vieira da Silva}

Doutor em Engenharia de Produção pela Universidade Federal de Santa Catarina - UFSC

Professor da Pontifícia Universidade Católica do Paraná - PUCPR

wesley.vieira@pucpr.br (Brasil)

\section{Ângela Cristiane Santos Póvoa}

Doutora em Administração de Empresas pela Universidade Presbiteriana Mackenzie - Mackenzie

Professora da Pontifícia Universidade Católica do Paraná - PUCPR

angela.povoa@pucpr.br (Brasil)

\section{Hélio Gomes de Carvalho}

Doutor em Engenharia de Produção pela Universidade Federal de Santa Catarina - UFSC

Professor do Centro Universitário Internacional - UNINTER

heliocarvalho@gmail.com(Brasil)

\section{RESUMO}

As organizações, em geral, têm buscado a inovação como meio para obtenção de vantagem competitiva. No contexto das micro e pequenas empresas (MPEs), essa prática tem sido apoiada pelo Serviço Brasileiro de Apoio às Micro e Pequenas Empresas (SEBRAE) por meio do programa Agentes Locais de Inovação (ALI), que tem como objetivo fortalecer a prática da inovação pela identificação de oportunidades para inovar. A principal ferramenta utilizada neste trabalho é o Radar da Inovação, que tem como base o trabalho original de Sawhney, Wolcott e Arroniz (2006). Este artigo buscou alcançar dois objetivos i) analisar como as MPEs podem utilizar o Radar como instrumento para a construção de estratégias para a inovação; ii) analisar comparativamente os setores participantes da amostra no que se refere à dimensão em que ocorre a inovação bem como a importância da inovação para cada setor analisado. A amostra do estudo foi composta de 1139 micro e pequenas empresas que aderiram ao programa ALI em 2012, Localizadas no Estado do Paraná. Os dados foram analisados por meio de testes estatísticos como o de Kruskal-Wallis, Mann-Whitney entre outros. Os resultados obtidos mostraram que as MPEs inovam por meio de dimensões semelhantes do Radar, ainda que pertençam a setores diferentes. Contudo, a diferença entre os setores analisados está na intensidade da inovação, que mostrou-se mais robusta no setor de software e mais fraca no setor moveleiro. Verificou-se ainda que muitas dimensões do Radar foram pouco exploradas, o que mostra grande potencial para obtenção de vantagem competitiva por meio da inovação.

Palavras-chave: Inovação; Radar da Inovação; Dimensões da Inovação; Programa Agentes Locais de Inovação (ALI); Inovação em Micro e Pequenas Empresas (MPEs). 


\section{INTRODUÇÃO}

A preocupação com a geração de vantagem competitiva para as micro e pequenas empresas (MPEs) tem se mostrado evidente nas ações de órgãos de apoio como o Serviço Brasileiro de Apoio às Micro e Pequenas Empresas (SEBRAE), tendo em vista que este tipo de empreendimento (de micro e pequeno porte) sofre de forma mais contundente os efeitos do acirramento da concorrência e da globalização dos mercados em razão de sua maior fragilidade financeira quando comparado aos empreendimentos de médio e grande porte. A inovação, à medida que permite à empresa desenvolver novas capacidades e recursos, pode ser apontada como fonte para a geração de vantagem competitiva (BARNEY, 1996). Nesse sentido, o Radar da Inovação originalmente proposto por Sawhney, Wolcott e Arroniz (2006), e adaptado para o contexto das MPEs por Bachmann (2008), tem o potencial de contribuir para o alcance de vantagem competitiva, uma vez que este aponta em quais dimensões as empresas de um determinado setor têm inovado, ao mesmo tempo em que sinaliza quais dimensões ainda são pouco exploradas e que, portanto, podem diferenciar uma empresa em relação aos seus concorrentes setoriais.

Nesse contexto, este trabalho buscou abordar as dimensões da inovação nas MPE de diversos setores econômicos e que atuam no Estado do Paraná, por meio da ferramenta Radar da Inovação do Programa Agentes Locais de Inovação (ALI) promovido pelo SEBRAE. De forma mais específica, o objetivo deste trabalho foi o de analisar como o Radar da Inovação pode auxiliar as empresas na construção de estratégias para a inovação de forma a contribuir para o alcance de vantagem competitiva. Também foi objetivo deste trabalho fazer uma análise comparativa entre as empresas dos diversos setores analisados com o intuito de identificar em quais dimensões do Radar as empresas têm inovado e também qual tem sido a intensidade da inovação nos diferentes setores.

Tendo em vista a relevância das MPEs para a economia brasileira, sobretudo no que se refere à geração de emprego e renda, este trabalho se justifica em razão de apontar caminhos e possibilidades para a inovação para um segmento de empresas economicamente mais frágil. Além disso, como contribuição teórica, este trabalho faz uma análise comparativa entre os vários setores, identificando aqueles que são menos ou mais dedicados à inovação, lançando luz sobre um tipo de empreendimento ainda pouco estudado. Como contribuição prática, este conhecimento pode vir a servir como base para orientar a ação de órgãos de apoio como o próprio SEBRAE, uma vez que permite compreender de

Revista de Administração e Inovação, São Paulo, v. 12, n.4 p. 162-186, out./dez. 2015. 
forma mais profunda as especificidades dos empreendimentos de pequeno porte no que se refere à inovação.

Os resultados obtidos permitiram observar que as empresas participantes da amostra buscam inovar principalmente nas dimensões "plataforma" e "marca", sendo tais dimensões presentes mesmo para empresas de diferentes setores. A implicação desse achado é que várias outras dimensões possíveis para a inovação são pouco utilizadas e, dessa forma, identifica-se grande potencial para geração de vantagem competitiva para as MPEs que se dedicarem à inovação em dimensões ainda pouco exploradas. Contudo, embora as empresas inovem por meio de dimensões semelhantes, observa-se que a intensidade da inovação varia significativamente de um setor para o outro. Nesse sentido, foi identificado que o setor de software mostrou-se muito mais propenso à inovação do que o setor moveleiro, que mostrou-se o menos inovador.

Em síntese, o Radar da Inovação pode efetivamente ser utilizado como ferramenta para o alcance de vantagem competitiva à medida que aponta as dimensões que têm sido pouco exploradas e que podem vir a constituir-se num diferencial competitivo.

O trabalho encontra-se estruturado em cinco seções que podem ser sumarizadas da seguinte forma: a primeira seção traz a parte introdutória; a segunda traz o referencial teórico-empírico; a terceira trata dos procedimentos metodológicos; a quarta a apresentação e análise dos dados; e a quinta as considerações finais.

\section{INOVAÇÃO}

Com o passar dos anos, os indicadores tradicionais de inovação (OECD, 1981, 1992) evoluíram e passaram a abranger diferentes aspectos da inovação, não se limitando apenas a indicadores tecnológicos de Pesquisa e Desenvolvimento (P\&D) (Freeman \& Soete, 2009). Nesse sentido, o Manual de Oslo, que é utilizado como referência no tema em diversos países, inclusive no Brasil, define inovação como:

[...] a implementação de um produto (bem ou serviço) novo ou significativamente melhorado, ou um processo, ou um novo método de marketing, ou um novo método organizacional nas práticas de negócios, na organização do local de trabalho ou nas relações externas (OCDE \& FINEP, 2005, p. 55).

Baregheh, Rowley e Sambrook (2009) identificaram na literatura que as definições de inovação envolvem principalmente o atributo tipo (produto, processo, serviços etc.). O segundo atributo mais utilizado envolveu a natureza da inovação (novo, aperfeiçoamento etc.). Os outros atributos 
identificados envolveram meios (recursos etc.), contexto social (organizações, empresas, clientes etc.), estágios (criação, implementação, desenvolvimento etc.) e, em menor intensidade, objetivos.

Tidd, Bessant e Pavitt (2008) consideram quatro tipos de inovação: inovação de produto (bem e serviço); inovação de processo; inovação de posição, que envolve mudanças no contexto em que são lançados produtos e serviços; e inovação de paradigma, que envolvem mudanças nos paradigmas (modelos mentais) que orientam as atividades da empresa.

Davila, Epstein e Shelton (2007) dividem a inovação em dois tipos principais: inovação tecnológica, caracterizada por mudanças em produtos e serviços, processos tecnológicos e tecnologias capacitadoras; e inovação no modelo de negócios, caracterizada por mudanças na proposição de valor, cadeia de suprimentos e cliente alvo. Chesbrough (2007; 2010), Johnson, Christensen e Kagermann (2008) e Teece (2010) também destacam a importância dos modelos de negócio para a inovação. Para Chesbrough (2010), a inovação no modelo de negócios é tão importante quanto a inovação na tecnologia, pois uma mesma tecnologia comercializada de duas maneiras distintas irá produzir dois resultados distintos. Além disso, uma tecnologia banal seguida de um bom modelo de negócios pode ser mais valiosa do que uma tecnologia fantástica seguida de um fraco modelo de negócios.

Sawhney, Wolcott e Arroniz (2006) ampliaram o escopo das formas de inovar por meio da ferramenta denominada Radar da Inovação (figura 1), que apresenta doze dimensões possíveis para a inovação nos negócios, as quais são alicerçadas por quatro eixos principais: as ofertas de uma empresa; os clientes; os processos; e os pontos de presença que levam suas ofertas ao mercado.

Figura 1 - Radar da Inovação

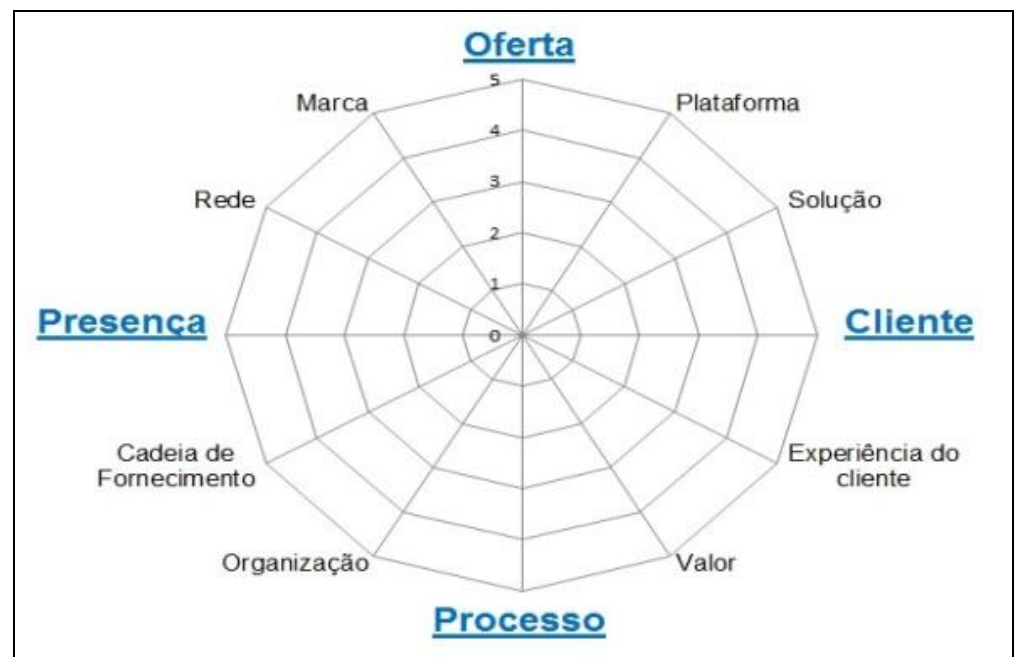

Fonte: adaptado de Sawhney, Wolcott e Arroniz (2006, p. 77). 
Cada dimensão oferece para a empresa diferentes modos de inovar (Sawhney, Wolcott \& Arroniz, 2006):

1. Oferta: envolve a criação de novos produtos ou serviços.

2.Plataforma: envolve o uso de componentes ou blocos comuns para criar diferentes produtos.

3. Solução: compreende a criação de ofertas integradas e customizadas.

4. Cliente: inclui o descobrimento de novas necessidades dos clientes ou a identificação de segmentos não atendidos.

5.Experiência: do cliente abrange todo e qualquer ponto de interação (contato) com o cliente.

6. Valor: inclui a redefinição de como a companhia obtém receitas.

7. Processo: abrange principalmente aumento da performance nos processos.

8. Organização: envolve mudanças na forma, função ou escopo de atividades da empresa.

9. Cadeia de fornecimento: envolve mudanças na cadeia, como no fluxo de informações, e relações de terceirização.

10. Presença: compreende principalmente novos canais de distribuição e novos pontos de presença.

11. Redes: envolve principalmente o uso de tecnologias da informação e comunicação de forma integrada com as ofertas.

12. Marca: inclui a expansão da marca para novos domínios.

Assim, o Radar da Inovação pode auxiliar as empresas na realização de um autodiagnostico geral das inovações nos negócios e também na identificação de oportunidades de inovação, principalmente por meio da comparação com os concorrentes (Sawhney, Wolcott \& Arroniz, 2006).

\subsection{Inovação e vantagem competitiva}

Em razão da globalização e da alta competitividade dos mercados, as empresas buscam a inovação para se diferenciar dos concorrentes e melhorar seu desempenho e, consequentemente, sua vantagem competitiva (Anthony, 2012; Carvalho, Reis \& Cavalcante, 2011; Ireland \& Webb, 2007; Tidd, Bessant \& Pavitt, 2008). A vantagem competitiva, conforme definida por Vasconcelos e Cyrino (2000) é a ocorrência de níveis de desempenho econômico acima da média do mercado em virtude das estratégias adotadas pelas empresas. Nessa perspectiva, o investimento em inovação pode favorecer o 
alcance de vantagem competitiva na medida que propicia as condições para um desempenho financeiro superior.

Winter (1987) coloca que alguns tipos de inovações em processos forneceriam bases para uma vantagem competitiva mais duradoura, uma vez que seriam menos sujeitos a observação e imitação pelos concorrentes. Porter (1996) argumenta que, um dos fatores necessários para o alcance de vantagem competitiva está na escolha de um conjunto de atividades fundamentalmente diferente daquelas exercidas pelos concorrentes, de forma a gerar uma oferta diferenciada. Nessa perspectiva, ao inovar em direções pouco exploradas pelos concorrentes, as empresas podem alcançar uma oferta diferenciada que pode vir a tornar-se fonte de vantagem competitiva. Barney (1996) lembra que determinadas empresas, a exemplo da Sony, exibem uma vantagem competitiva sustentável sobre seus competidores não porque suas inovações não sejam copiadas, mas porque a empresa consegue explorar suas capacitações com maior agilidade. Jacobson (1992) coloca que, por meio da inovação, pequenas empresas poderiam responder mais rapidamente a mudanças na demanda, o que poderia compensar seus maiores custos médios, resultantes de sua menor economia de escala.

Barney (1996) coloca o constante desafio enfrentado pelas empresas, ao qual designou ser o "paradoxo da imitabilidade". Nesta perspectiva, quanto menos custoso for para uma firma desenvolver ou adquirir os recursos que lhe dariam vantagem competitiva, tanto mais fácil será, provavelmente, para seus concorrentes os desenvolverem ou adquirirem por custo semelhante, gerando apenas paridade competitiva na indústria. A solução para esse paradoxo talvez esteja no constante incentivo à inovação, conforme apontado por Hill e Deeds (1996).

Nesse sentido, Basso, Cruz e Kimura (2010), Madrid-Guijarro, García-Pérez-de-Lema e Van Auken (2013) e Sbragia e Andreassi (2002) analisaram a relação entre inovação e desempenho. Sbragia e Andreassi (2002) buscaram compreender as relações entre o esforço de inovação e um conjunto de indicadores de lucratividade, participação do mercado e faturamento (gerado por produtos novos ou melhorados), e os resultados mostraram que os investimentos em P\&D estão fortemente associados com a futura participação de novos produtos na receita total das empresas. Basso, Cruz e Kimura (2010) também identificaram a existência de influência positiva da inovação no desempenho financeiro das empresas brasileiras. Madrid-Guijarro, García-Pérez-de-Lema e Van Auken (2013) verificaram que a inovação esteve positivamente relacionada com o desempenho de MPEs espanholas tanto em períodos econômicos de crescimento quanto de recessão. Tais achados mostram a relevância da inovação como fator que afeta o desempenho organizacional.

Revista de Administração e Inovação, São Paulo, v. 12, n.4 p. 162-186, out./dez. 2015. 


\subsection{Programa agentes locais de inovação (ali) SEBRAE}

O Serviço Brasileiro de Apoio às Micro e Pequenas Empresas (SEBRAE) desenvolve o programa Agentes Locais de Inovação com o objetivo de fomentar a prática da inovação para as micro e pequenas empresas e sensibilizar os empresários sobre a importância da inovação como fator de sucesso (SEBRAE-PR, 2014).

Após a adesão ao programa, há uma visita do Agente Local de Inovação (ALI) para um diagnóstico inicial da inovação da empresa por meio do Radar da Inovação, denominado R0. Em seguida, o ALI elabora um plano de ações e soluções inovadoras, que deverá ser implementado sob responsabilidade da empresa. Por fim, o projeto prevê o acompanhamento do ALI em um segundo momento, possibilitando um novo ciclo de diagnóstico, denominado R1, para observar a evolução da empresa (figura 2). Adicionalmente, o programa é gratuito para o empresário e os Agentes Locais de Inovação são bolsistas do Conselho Nacional de Desenvolvimento Científico e Tecnológico (CNPq) por dois anos, recém-formados até três anos, capacitados no tema inovação pelo próprio SEBRAE e acompanhados por um consultor sênior (SEBRAE, 2014).

\section{Figura 2 - Etapas do Programa Agentes Locais de Inovação (ALI)}

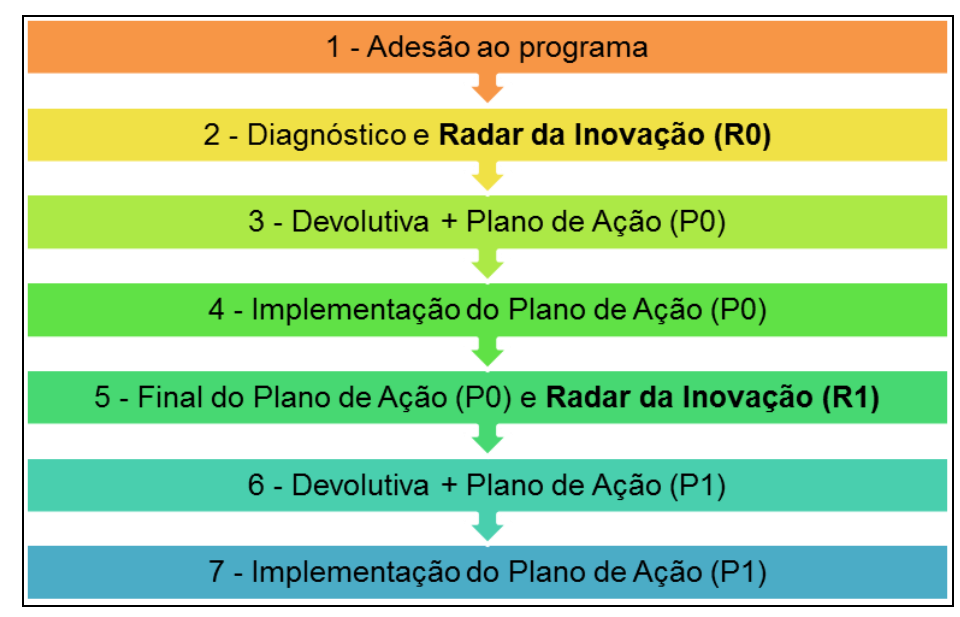

Fonte: Adaptado de SEBRAE (2014).

O Radar da Inovação utilizado no projeto foi elaborado em 2008 por Bachmann \& Associados (Bachmann, 2009) e é baseado no radar proposto originalmente por Sawhney, Wolcott e Arroniz em 2006 (Sawhney, Wolcott \& Arroniz, 2006). A principal diferença é a inclusão da dimensão Ambiência Inovadora, que tem como objetivo avaliar o ambiente propício à inovação dentro da empresa por meio de evidências como o a existência de colaboradores capacitados, existência de programas de sugestão, realização de acordos de transferência de tecnologia, utilização de recursos de órgãos de fomento 
como a Financiadora de Estudos e Projetos (FINEP), entre outros. (Bachmann \& Destefani, 2008, P. $13)$.

O projeto tem amplitude nacional e vários estudos já foram publicados (Capeleiro \& Araújo, 2013; Carvalho et al., 2015; Dezinot, 2014; Oliveira et al., 2011, 2014; Silva Néto \& Teixeira, 2011, 2014), dentre os quais se destacam: o estudo de Silva Néto e Teixeira (2011, p. 205-229), que compara o Radar da Inovação de micro e pequenas empresas do setor têxtil em Sergipe localizadas na capital Aracaju e no interior; o estudo de Silva Néto e Teixeira (2014), que apresenta um panorama da inovação em Sergipe e destaca a dimensão plataforma como a mais desenvolvida pelas MPE dos cinco setores abordados; e o estudo de Oliveira et al. (2014, p. 115-137) realizado em Pernambuco, que propõe a normalização das dimensões do Radar da Inovação para possibilitar a comparação entre diferentes setores.

\section{PROCEDIMENTOS METODOLÓGICOS}

Este trabalho buscou alcançar dois objetivos principais: i) Analisar como as MPEs podem utilizar o radar como instrumento para a construção de estratégias para a inovação, favorecendo o alcance de vantagem competitiva; ii) Analisar comparativamente os setores participantes da amostra no que se refere a dimensão em que ocorre a inovação bem como a importância da inovação para cada setor analisado.

Para alcançar o primeiro objetivo, procedeu-se uma análise dos dados levantados pelos ALI e que forneciam as informações acerca das dimensões mais utilizadas pelas MPEs em suas atividades de inovação. A partir desse levantamento, foi possível estabelecer as principais dimensões utilizadas pelas empresas no processo de inovação, bem como as dimensões pouco exploradas que podem vir a constituir-se em fonte de vantagem competitiva. Já o segundo objetivo proposto lançou mão de ferramental estatístico com o objetivo de analisar se a intensidade da inovação entre os setores analisados era significativamente distinta.

Os dados relativos ao Radar da Inovação e coletados pelos ALI foram organizados em uma planilha eletrônica pelo orientador dos Agentes (um dos autores da pesquisa) e, em seguida, importados para o programa estatístico SPSS (IBM SPSS Statistics 21). Primeiramente, diagramas de caixa e bigodes foram traçados para identificar possíveis erros de preenchimento, conforme sugere

Revista de Administração e Inovação, São Paulo, v. 12, n.4 p. 162-186, out./dez. 2015. 
Field (2009, p. 95-96). A grande vantagem de traçar esse tipo de gráfico é a identificação da linha que contém o erro.

Em seguida, foi realizado o teste de normalidade de Kolmogorov-Smirnov das 13 dimensões do Radar da Inovação para cada setor de atividade, pois se a análise envolve a comparação de grupos, a distribuição global não tem importância, mas sim a distribuição de cada grupo (Field, 2009, P. 115). O resultado desse teste indicou distribuições não normais, exceto para uma dimensão de um único setor. Assim, o teste de homogeneidade das variâncias, que também é requisito para a utilização de outros testes paramétricos, não foi necessário (Field, 2009, P. 86).

Para verificar se havia diferenças significativas entre as médias das dimensões dos diversos setores, e assim avaliar se a intensidade da inovação era estatisticamente distinta, foi utilizado o teste de Kruskal-Wallis, que comprovou que havia diferenças significativas entre os setores. Contudo, esse teste não indica onde as diferenças estão e, para isso, foi necessário utilizar testes post-hoc de MannWhitney. Para verificar todas as combinações possíveis entre os setores, utilizou-se a correção de Bonferroni, que divide o valor crítico de 0,05 pelo número de testes realizados (Field, 2009, p. 492498). Também foi utilizada a estimativa de Monte Carlo para a significância, pois não foi possível utilizar a significância exata em alguns casos, mesmo aumentando a memória do espaço de trabalho (workspace) do programa, que é utilizada por testes não paramétricos, para aproximadamente 2 GB (IBM, 2014). A Figura 3 ilustra os testes utilizados na pesquisa em etapas.

\section{Figura 3 - Testes utilizados na pesquisa.}

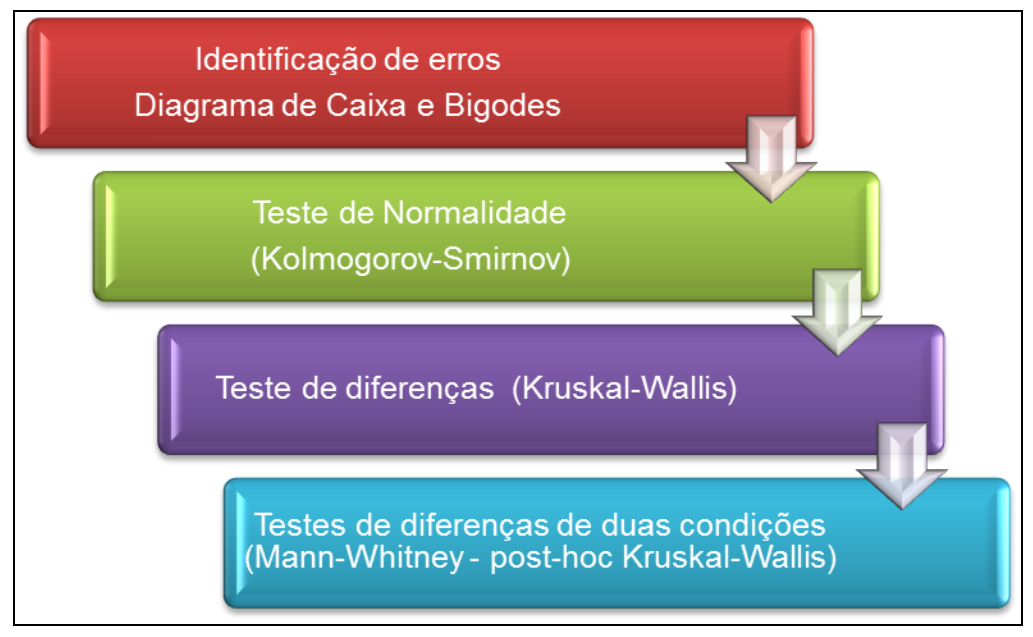

Fonte: Elaborado pelos autores.

Os resultados para esses testes são apresentados na próxima seção, assim como a análise das frequências, a análise descritiva da amostra e a análise estatística dos dados. 


\subsection{Caracterização da pesquisa}

Em relação à natureza, esta foi uma pesquisa aplicada. Em relação à forma de abordagem do problema de pesquisa, foi utilizada uma abordagem quantitativa. Em relação aos objetivos da pesquisa, esta foi uma pesquisa descritiva. Já em relação à investigação dos dados, foi uma pesquisa não experimental, de levantamento, bibliográfica e de campo.

Em relação ao nível de análise, à unidade de análise e ao corte temporal, o nível de análise foi organizacional, a unidade de análise foi o conjunto de micro e pequenas empresas participantes do programa Agentes Locais de Inovação no Paraná e o corte temporal foi do tipo transversal, pois abrangeu apenas o primeiro Radar da Inovação (R0) do programa ALI, que mapeou a situação vivenciada pelas empresas no tocante à inovação.

\subsection{Coleta de dados}

A população considerada abrangeu as micro e pequenas empresas que atuam no Estado do Paraná nos setores da agroindústria, construção civil, metal mecânico, moveleiro, software, turismo, varejo e vestuário. Já a amostra foi composta pelas micro e pequenas empresas desses setores que aderiram ao programa ALI no ciclo 2012-2014 nas cidades de Cianorte, Curitiba, Londrina, Maringá e Ponta Grossa. Assim, a amostragem foi não probabilística por adesão, pois as empresas participaram voluntariamente do programa após consulta. A coleta de dados ocorreu no ano de 2013 por meio de questionários preenchidos pelos ALI após visitas e entrevistas nas empresas, totalizando 1139 empresas pesquisadas no período.

O questionário do Radar da Inovação foi composto por 42 questões que abrangeram as 13 dimensões. A cada questão foi atribuído um escore: 1 (baixo), 3 (médio) e 5 (alto). A Figura 4 ilustra as dimensões do radar da inovação e as questões que compõem cada dimensão, ao passo que o Anexo A apresenta um resumo detalhado das questões que compõem cada dimensão. Em relação à validade, destaca-se que o Radar da Inovação está alicerçado na literatura, especialmente com base em Sawhney, Wolcott e Arroniz (2006). Em relação à confiabilidade, destaca-se o elevado número de estudos realizados por meio do Radar da Inovação, conforme apresentado no referencial teórico.

Revista de Administração e Inovação, São Paulo, v. 12, n.4 p. 162-186, out./dez. 2015. 


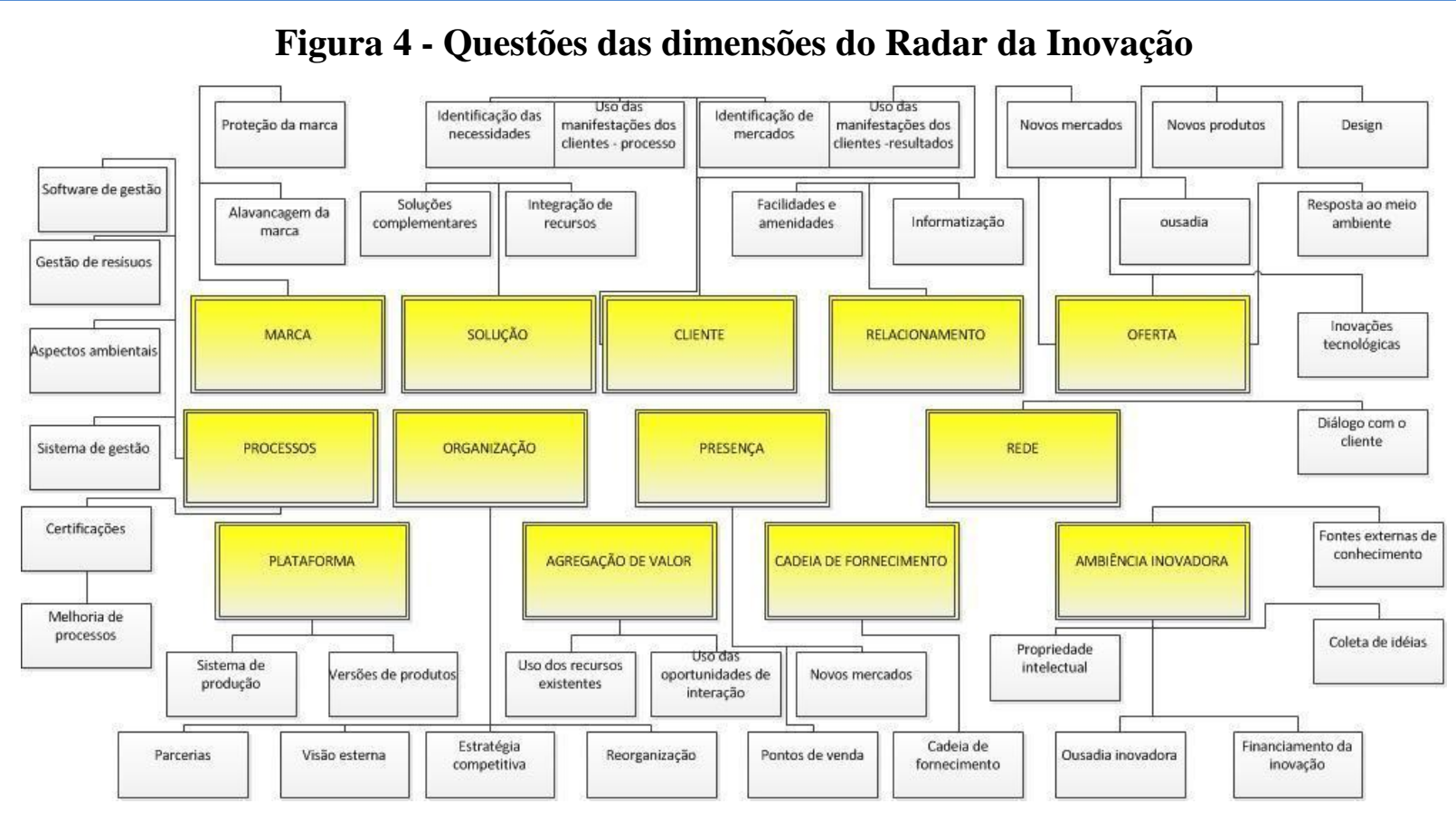

Fonte: Oliveira et al. (2011).

As respostas dos questionários foram transferidas pelos ALI para a plataforma do SEBRAE, a qual calculou os valores para cada dimensão, por meio da média das questões que a compõem. Os valores das dimensões de todas as empresas foram coletados pelos ALI da plataforma do SEBRAE e disponibilizados a um dos pesquisadores por meio de planilhas eletrônicas.Adicionalmente, para compor o cadastro e o perfil da empresa, foram anotadas outras informações como número de empregados e tempo de existência da empresa em anos. Esses dados foram condensados em uma única planilha e depois foram importados para o programa estatístico SPSS (IBM SPSS Statistics 21) para análise.

\section{APRESENTAÇÃO E DISCUSSÃO DOS RESULTADOS}

A amostra da pesquisa foi composta por oito diferentes setores da economia: agroindústria, construção civil, metal mecânico, moveleiro, software, turismo, varejo e vestuário.

A Tabela 1apresenta a distribuição da amostra por meio de uma tabulação cruzada entre as cidades e os setores. 


\section{Tabela 1 - Número de empresas por cidade e setor}

\begin{tabular}{|c|c|c|c|c|c|c|c|c|c|}
\hline Cidade/Setor & Agroind. & Constr. & $\begin{array}{c}\text { Metal } \\
\text { Mec. }\end{array}$ & Mov. & SW & Turismo & Varejo & Vest. & Total \\
\hline Cianorte & 0 & 0 & 0 & 0 & 0 & 0 & 0 & 60 & 60 \\
\hline Curitiba & 58 & 0 & 0 & 0 & 51 & 0 & 0 & 0 & 109 \\
\hline Londrina & 56 & 0 & 0 & 0 & 60 & 0 & 0 & 0 & 116 \\
\hline Maringá & 128 & 60 & 190 & 40 & 52 & 59 & 110 & 159 & 798 \\
\hline Ponta Grossa & 0 & 0 & 0 & 0 & 0 & 56 & 0 & 0 & 56 \\
\hline Total & 242 & 60 & 190 & 40 & 163 & 115 & 110 & 219 & 1139 \\
\hline
\end{tabular}

Fonte: Os autores com base nos dados da pesquisa.

A figura 5 apresenta a distribuição da amostra por cidades e a

figura 6 apresenta a distribuição da amostra por setores. A partir desses gráficos, foi possível observar que a maioria das empresas da amostra estão na cidade de Maringá. Já a figura 5 apresenta a distribuição da amostra pelos setores analisados.

\section{Figura 5 - Distribuição da amostra por Cidades}

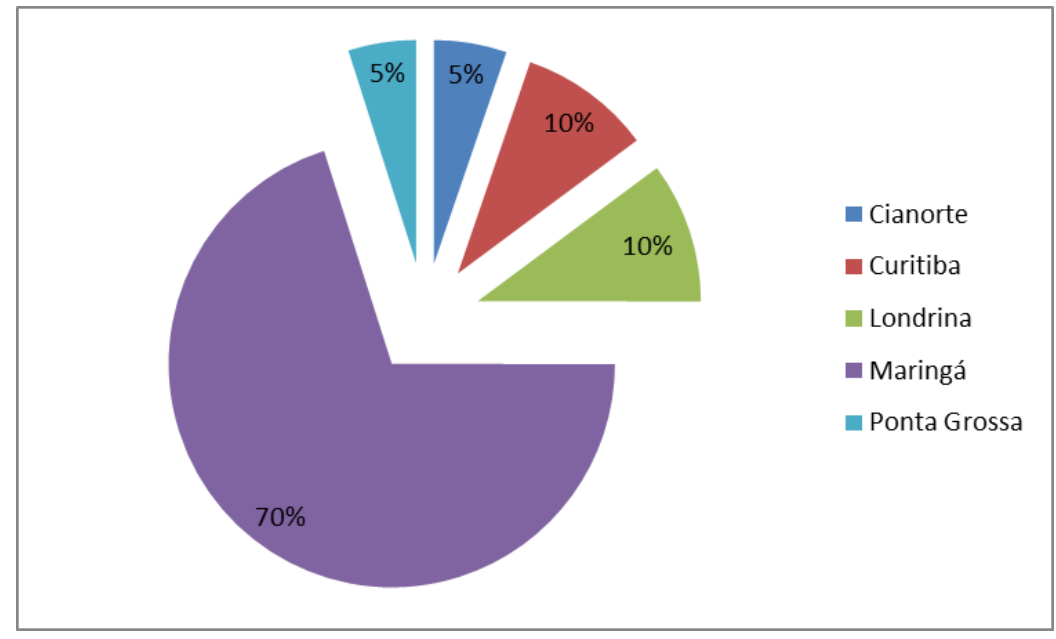

Nota: Amostra constituída por 1.139 empresas.

Fonte: Os autores com base nos dados da pesquisa. 
Figura 6 - Distribuição da amostra por setores

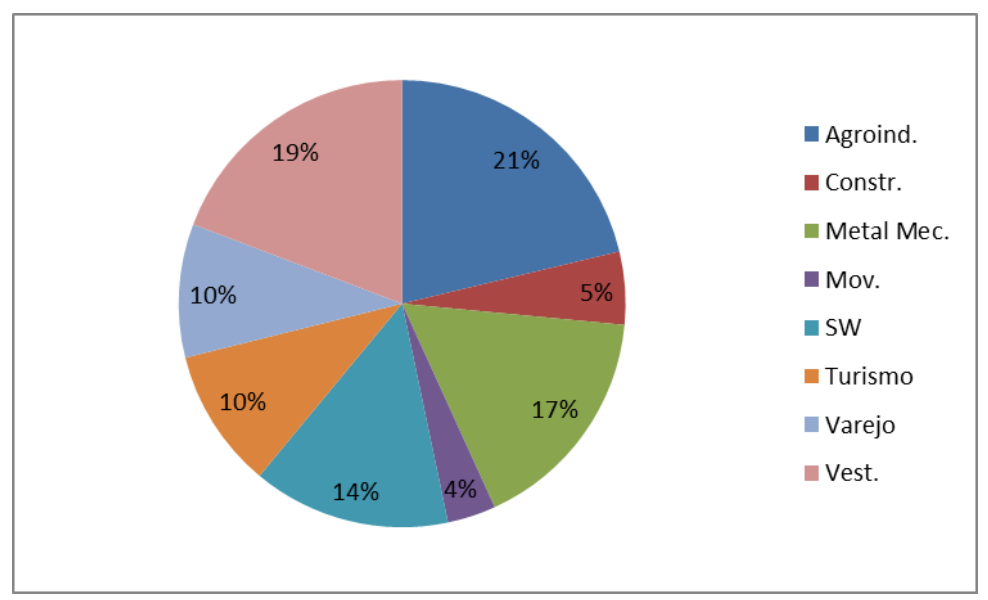

Nota: Amostra constituída por 1.139 empresas

Fonte: os autores com base nos dados da pesquisa.

Embora haja uma concentração geográfica, a participação dos setores na amostra encontra-se mais bem distribuída, uma vez que o maior setor (agroindústria) representou $21 \%$ da amostra, ao passo que cinco dos setores analisados (metal mecânico, software, turismo, varejo e vestuário) representaram entre $10 \%$ a $20 \%$ da amostra. Apenas dois setores (construção civil e moveleiro) representaram 5\% ou menos de empresas na amostra.

\subsection{Análise descritiva da amostra}

A primeira análise descritiva realizada abrangeu a amostra como um todo e está ilustrada na Tabela 2, que apresenta as estatísticas básicas das dimensões do Radar da Inovação, e também o número de empregados e o tempo de existência da empresa em anos. A partir da Tabela 2, foi possível observar que a maioria das dimensões do Radar da Inovação estão abaixo de 3, o que representa a média das pontuações, que variou entre 1 e 5. Além disso, o número médio de empregados das empresas foi igual a 14 e o tempo médio dessas empresas no mercado foi de 10 anos.

Tabela 2 - Análise Descritiva

\begin{tabular}{|c|c|c|c|c|c|c|c|c|c|}
\hline & Válido & Ausente & Média & $\begin{array}{c}\text { Erro } \\
\text { padrão }\end{array}$ & Mediana & $\begin{array}{c}\text { Desvio } \\
\text { padrão }\end{array}$ & Var. & Mín & Máx \\
\hline Oferta & 1139 & 0 & 2,37 & 0,03 & 2,20 & 1,09 & 1,20 & 1,00 & 5,00 \\
\hline Plataf. & 1139 & 0 & 3,73 & 0,03 & 4,00 & 1,07 & 1,15 & 1,00 & 5,00 \\
\hline Marca & 1139 & 0 & 3,20 & 0,03 & 3,00 & 0,95 & 0,91 & 1,00 & 5,00 \\
\hline Clientes & 1139 & 0 & 2,28 & 0,03 & 2,00 & 0,93 & 0,87 & 1,00 & 5,00 \\
\hline Soluções & 1139 & 0 & 1,96 & 0,03 & 2,00 & 1,10 & 1,22 & 1,00 & 5,00 \\
\hline Relac. & 1139 & 0 & 2,08 & 0,03 & 2,00 & 1,10 & 1,21 & 1,00 & 5,00 \\
\hline
\end{tabular}


Radar da inovação como ferramenta para o alcance de vantagem competitiva para micro e pequenas

empresas

\begin{tabular}{|c|c|c|c|c|c|c|c|c|c|}
\hline Agreg. valor & 1139 & 0 & 1,60 & 0,03 & 1,00 & 0,84 & 0,71 & 1,00 & 5,00 \\
\hline Processos & 1139 & 0 & 1,66 & 0,02 & 1,70 & 0,55 & 0,31 & 1,00 & 4,30 \\
\hline Organização & 1139 & 0 & 1,76 & 0,02 & 1,50 & 0,80 & 0,64 & 1,00 & 5,00 \\
\hline Cadeia forn. & 1139 & 0 & 1,77 & 0,03 & 1,00 & 1,16 & 1,34 & 1,00 & 5,00 \\
\hline Presença & 1139 & 0 & 1,73 & 0,03 & 1,00 & 0,95 & 0,91 & 1,00 & 5,00 \\
\hline Rede & 1139 & 0 & 1,86 & 0,04 & 1,00 & 1,24 & 1,55 & 1,00 & 5,00 \\
\hline Amb. Inov. & 1139 & 0 & 1,69 & 0,02 & 1,50 & 0,54 & 0,29 & 1,00 & 5,00 \\
\hline $\begin{array}{c}\text { No. } \\
\text { Empreg. }\end{array}$ & 1096 & 43 & 14,09 & 0,52 & 9,00 & 17,29 & 298,97 & 1,00 & 283,00 \\
\hline Tempo & 1104 & 35 & 10,06 & 0,23 & 8,00 & 7,61 & 57,98 & 1,00 & 56,00 \\
\hline
\end{tabular}

Fonte: Os autores com base nos dados da pesquisa

$\mathrm{Na}$ Tabela 3, ao analisar as médias das dimensões utilizadas para cada setor, é possível observar que as dimensões "plataforma" e "marca" foram as mais utilizadas, mesmo para diferentes setores de atuação, de forma semelhante ao que foi observado por Silva Néto e Teixeira (2014) em MPEs de cinco setores em Sergipe.A dimensão "oferta" foi a segunda mais presente dentre os setores analisados, seguida pelas dimensões "clientes" como terceira mais presente, e "relacionamento" e "soluções" em quarta posição. A Tabela 3apresenta as médias de todas as dimensões utilizadas pelas empresa em cada setor analisado. Em destaque, estão as maiores dimensões por setor.

Tabela 3 - Média das Dimensões da Inovação para cada Setor

\begin{tabular}{|c|c|c|c|c|c|c|c|c|}
\hline $\begin{array}{c}\text { Setor } \\
\text { Dimensão }\end{array}$ & Agroind. & Constr. & Metal Mec. & Mov. & SW & Turismo & Varejo & Vest. \\
\hline Oferta & 2,39 & 1,77 & 1,70 & 2,73 & 2,44 & 2,03 & 3,20 & 2,72 \\
\hline Plataf. & 3,62 & 3,88 & 3,80 & 3,50 & 3,31 & 3,81 & 3,80 & 4,01 \\
\hline Marca & 3,21 & 3,08 & 2,90 & 2,70 & 3,48 & 3,28 & 3,05 & 3,40 \\
\hline Clientes & 2,23 & 1,94 & 1,58 & 1,64 & 2,99 & 2,13 & 2,00 & 2,82 \\
\hline Soluções & 1,62 & 1,43 & 1,47 & 1,40 & 2,85 & 2,31 & 2,26 & 2,00 \\
\hline Relac. & 1,53 & 1,87 & 1,88 & 1,98 & 2,42 & 2,64 & 2,17 & 2,37 \\
\hline Agreg. valor & 1,39 & 1,47 & 1,33 & 1,45 & 2,29 & 1,83 & 1,32 & 1,64 \\
\hline Processos & 1,56 & 1,55 & 1,67 & 1,56 & 1,96 & 1,48 & 1,55 & 1,73 \\
\hline Organização & 1,63 & 1,55 & 1,41 & 1,48 & 2,62 & 1,58 & 1,80 & 1,73 \\
\hline Cadeia forn. & 1,68 & 1,83 & 1,38 & 1,75 & 2,04 & 2,06 & 1,62 & 1,94 \\
\hline Presença & 1,80 & 1,38 & 1,53 & 1,98 & 1,88 & 1,66 & 1,41 & 1,99 \\
\hline Rede & 1,36 & 1,63 & 1,48 & 1,10 & 2,71 & 2,17 & 1,78 & 2,19 \\
\hline Amb. Inov. & 1,55 & 1,50 & 1,45 & 1,49 & 2,20 & 1,62 & 1,91 & 1,68 \\
\hline
\end{tabular}

Fonte: Os autores com base nos resultados da pesquisa

Tomando como base a Tabela 3, é possível observar que, mesmo atuando em setores distintos, as empresas analisadas concentraram-se seus esforços inovadores em dimensões semelhantes. Todos os setores apontaram as dimensões marca e plataforma como as mais presentes. Em contrapartida, há 
dimensões do Radar pouco exploradas pelas empresas quando decidem inovar. Dimensões como processos, organização, rede, cadeia de fornecedores e ambiente inovador apresentaram as menores médias em todos os setores analisados. Tal achado mostra o potencial para a geração de vantagem competitiva por parte das MPEs que compuseram a amostra, uma vez que estas podem passar a explorar dimensões da inovação ainda pouco exploradas pelos concorrentes setoriais, o que pode vir a constituir-se num diferencial estratégico (Sawhney, Wolcott, \& Arroniz, 2006).

A Figura 7 permite visualizar as principais dimensões do Radar separadas por setores e, embora as empresas em geral busquem inovar em dimensões semelhantes, é necessário apontar que a intensidade dessa inovação é distinta para setores distintos.

Figura 7 - Radares da Inovação por setor

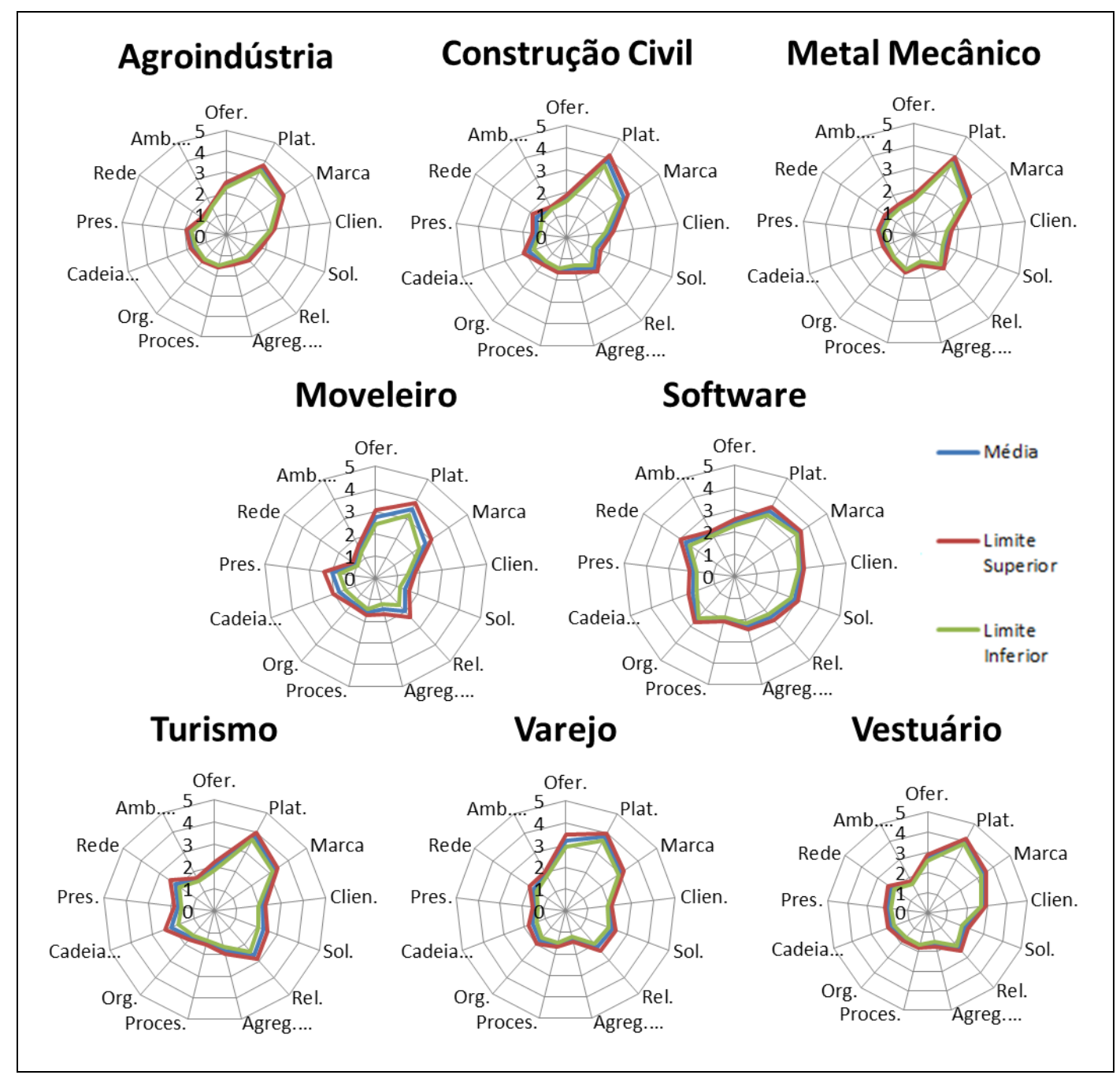

Fonte: Os autores com base nos resultados da pesquisa.

Os setores de software e de vestuário se destacaram positivamente no sentido de possuírem médias superiores em quase todas as dimensões, o que significa maior intensidade de inovação. Em 
contraposição, os setores metal mecânico, construção civil e agroindústria apresentaram as menores médias para a maioria das dimensões analisadas.

A figura 7 permite observar ainda que cada setor tem uma forma distinta da média no gráfico Radar da Inovação. É possível observar nos radares os limites superiores e inferiores da margem de erro. A margem de erro para 95\% é calculada como o erro padrão multiplicado por 1,96 (M erro = 1,96 $\mathrm{x}$ Erro Padrão). Já o limite superior é igual à média somada da margem de erro ( $\mathrm{L}$ sup = média $+\mathrm{M}$ erro), enquanto o limite inferior é igual a média decrescida da margem de erro ( $\mathrm{L}$ inf = média $-\mathrm{M}$ erro) (FIELD, 2009, p. 47). Em geral, ao comparar as margens de erro com a média, a grande maioria foi baixa, pois poucos casos foram superiores a $10 \%$.

Os radares da figura 7 apresentam uma boa perspectiva em relação às diferenças entre os setores. Contudo, não é possível afirmar com precisão se os setores são significativamente diferentes no que se refere à intensidade em que acessam cada dimensão e por essa razão, foram realizados testes estatísticos específicos, os quais são apresentados nas linhas que se seguem.

\subsection{Análise estatística e discussão dos resultados}

Sabe-se que a premissa da normalidade é exigida para a realização de muitos testes estatísticos. Para tanto, foi realizado o teste de Kolmogorov-Smirnov para verificar a normalidade das variáveis para a amostra como um todo e, em seguida, para cada setor de atividade. Nesse teste, se a significância for menor que $0,05(\mathrm{p}<0,05)$, a amostra não possui uma distribuição normal.

No teste realizado para cada setor, todos os resultados apontaram para distribuições não normais, exceto o setor moveleiro na dimensão plataforma $(\mathrm{p}=0,123)$, o qual foi o único teste com p>0,05. Contudo, acredita-se que o baixo número de amostras $(n=40)$ contribuiu para esse resultado. Para a utilização de testes paramétricos, é necessário que a amostra seja normalmente distribuída e que as variâncias sejam homogêneas.

O teste de Kruskal-Wallis foi utilizado para verificar se havia diferenças entre os setores nas diversas dimensões do Radar da Inovação, e assim analisar se a intensidade na inovação era diferente de um setor para o outro, ainda que esses inovassem, em média, nas mesmas dimensões.

A Tabela 4apresenta os resultados desse teste para cada uma das dimensões e como $\mathrm{p}<0,05 \mathrm{em}$ todas as dimensões, é possível concluir que há diferenças significativas entre os diversos setores.

Revista de Administração e Inovação, São Paulo, v. 12, n.4 p. 162-186, out./dez. 2015. 
Tabela 4 - Teste de Kruskal-Wallis

\begin{tabular}{|c|c|c|c|c|c|c|c|c|c|c|c|c|c|c|}
\hline & & fer. & lat. & arca & lien. & ol. & el. & $\begin{array}{l}\text { greg. } \\
\text { valor }\end{array}$ & roces. & rg. & $\begin{array}{l}\text { adeia } \\
\text { forn. }\end{array}$ & res. & ede & $\begin{array}{l}\text { mb. } \\
\text { Inov. }\end{array}$ \\
\hline \multicolumn{2}{|c|}{$\mathrm{H}$} & 177,81 & 41,90 & 66,41 & 308,54 & 220,53 & 129,97 & 154,42 & 68,97 & 198,09 & 38,66 & 53,50 & 152,05 & 219,38 \\
\hline \multicolumn{2}{|c|}{ Df } & 7 & 7 & 7 & 7 & 7 & 7 & 7 & 7 & 7 & 7 & 7 & 7 & 7 \\
\hline \multicolumn{2}{|c|}{$\begin{array}{c}\text { Significância } \\
\text { Assintótica }\end{array}$} & ,000 & ,000 & ,000 & ,000 & ,000 & ,000 & ,000 & ,000 & ,000 & ,000 & ,000 & ,000 & ,000 \\
\hline \multicolumn{2}{|c|}{ Sig. M. Carlo } &, $000^{\mathrm{c}}$ &, $000^{\mathrm{c}}$ &, $000^{\mathrm{c}}$ &, $000^{\mathrm{c}}$ &, $000^{\mathrm{c}}$ &, $000^{\mathrm{c}}$ &, $000^{\mathrm{c}}$ &, $000^{c}$ &, $000^{\mathrm{c}}$ &, $000^{\mathrm{c}}$ &, $000^{\mathrm{c}}$ &, $000^{c}$ &, $000^{c}$ \\
\hline \multirow{2}{*}{$\begin{array}{l}\text { Interv. } \\
\text { Conf. } \\
99 \%\end{array}$} & $\begin{array}{l}\text { Lim. } \\
\text { Inf. }\end{array}$ & 0,000 & 0,000 & 0,000 & 0,000 & 0,000 & 0,000 & 0,000 & 0,000 & 0,000 & 0,000 & 0,000 & 0,000 & 0,000 \\
\hline & $\begin{array}{l}\text { Lim. } \\
\text { Sup. }\end{array}$ & ,000 & ,000 & ,000 & ,000 & ,000 &, 000 & ,000 & ,000 & ,000 & ,000 & ,000 & ,000 & ,000 \\
\hline
\end{tabular}

c. Baseado em 10000 tabelas amostradas com valor inicial 2000000.

Fonte: Os autores.

Contudo, o teste de Kruskal-Wallis não identifica onde estão essas diferenças e análises posthoc (que significa literalmente "depois disso”) são necessárias. Assim, testes de Mann-Whitney foram realizados para cada uma das diversas combinações entre setores. Para garantir que o erro do tipo I (alfa) não fosse maior que 0,05 , foi utilizada a correção de Bonferroni, que basicamente implicou na divisão desse erro pela quantidade de testes que seriam realizados.

Para o cálculo do número de testes, utilizou-se a combinação dos 8 elementos agrupados dois a dois:

$$
C_{n, p}=\frac{n !}{p !(n-p) !}
$$

Onde $\mathrm{n}=8$ (setores) e $\mathrm{p}=2$ (agrupamento).

$$
C_{8,2}=\frac{8 !}{2 !(8-2) !} \Rightarrow C_{8,2}=\frac{8 !}{2 ! 6 !} \quad C_{8,2}=28
$$

Assim, o erro do tipo I $(0,05)$ foi dividido pelos 28 testes, resultando um erro do tipo I igual a aproximadamente 0,0018 para cada teste de Mann-Whitney. Os testes de Mann-Whitney forneceram diversas estatísticas de significância, conforme está apresentado na

Tabela 5.

Para a análise de significância, foi utilizado o valor da significância de Monte Carlo de duas extremidades (bilateral), uma vez que não houve previsões de qual grupo iria diferir. 
Tabela 5 -Teste Mann-Whitney entre os setores Agroindústria e Construção Civil

\begin{tabular}{|c|c|c|c|c|c|c|c|c|c|c|c|c|c|c|}
\hline & & Ofer. & Plat. & Marca & Clien. & Sol. & Rel. & $\begin{array}{l}\text { Agreg. } \\
\text { valor }\end{array}$ & Proces. & Org. & $\begin{array}{l}\text { Cadeia } \\
\text { forn. }\end{array}$ & Pres. & Rede & $\begin{array}{l}\text { Amb. } \\
\text { Inov. }\end{array}$ \\
\hline \multicolumn{2}{|c|}{$\begin{array}{c}\text { Mann- } \\
\text { Whitney U }\end{array}$} & 4297 & 6182 & 6742 & 5544 & 6657 & 5334 & 6814 & 7182 & 7171 & 6678 & 5347 & 6231 & 7068 \\
\hline \multicolumn{2}{|c|}{ Wilcoxon W } & 6127 & 35585 & 8572 & 7374 & 8487 & 34737 & 36217 & 9012 & 9001 & 36081 & 7177 & 35634 & 8898 \\
\hline \multicolumn{2}{|c|}{$\mathrm{Z}$} & $\begin{array}{c}- \\
4,948\end{array}$ & $\begin{array}{c}- \\
1,868\end{array}$ &,- 933 & $\begin{array}{c}- \\
2,887\end{array}$ & $\begin{array}{c}- \\
1,135\end{array}$ & $\begin{array}{c}- \\
3,586\end{array}$ &,- 879 &,- 135 & $\begin{array}{c}- \\
, 154\end{array}$ & $-1,163$ & $\begin{array}{c}- \\
3,461\end{array}$ & $\begin{array}{c}- \\
2,444\end{array}$ &,- 325 \\
\hline \multicolumn{2}{|c|}{$\begin{array}{l}\text { Sig. Assint. (2 } \\
\text { caudas) }\end{array}$} & ,000 & ,062 & ,351 & ,004 & ,256 &, 000 & ,379 & 893 & ,878 & ,245 & ,001 & ,015 & ,746 \\
\hline \multicolumn{2}{|c|}{$\begin{array}{c}\text { Sig. Monte } \\
\text { Carlo (2 } \\
\text { extremidades) }\end{array}$} &, $000^{\mathrm{b}}$ &, $061^{\mathrm{b}}$ &, $347^{\mathrm{b}}$ &, $003^{\mathrm{b}}$ &, $263^{\mathrm{b}}$ &, $000^{\mathrm{b}}$ &, $383^{\mathrm{b}}$ &, $896^{\mathrm{b}}$ &, $874^{\mathrm{b}}$ &, $274^{\mathrm{b}}$ &, $000^{\mathrm{b}}$ &, $017^{\mathrm{b}}$ &, $745^{\mathrm{b}}$ \\
\hline \multirow{2}{*}{$\begin{array}{l}\text { Interv. } \\
\text { Conf. } \\
99 \%\end{array}$} & $\begin{array}{l}\text { Lim. } \\
\text { Inf. }\end{array}$ & 0,000 & ,055 & ,335 & ,002 & ,251 & 0,000 &, 370 & ,888 & ,865 & ,262 & 0,000 & ,014 & ,733 \\
\hline & $\begin{array}{l}\text { Lim. } \\
\text { Sup. }\end{array}$ & ,000 & ,068 & ,359 & ,004 & ,274 & ,001 & ,396 & ,904 & ,883 & ,285 & ,001 & ,021 & ,756 \\
\hline \multicolumn{2}{|c|}{$\begin{array}{c}\text { Sig. Monte } \\
\text { Carlo (1 } \\
\text { extremidade) }\end{array}$} &, $000^{\mathrm{b}}$ &, $030^{\mathrm{b}}$ & $176^{\mathrm{b}}$ &, $002^{\mathrm{b}}$ &, $131^{\mathrm{b}}$ &, $000^{\mathrm{b}}$ &, $194^{\mathrm{b}}$ &, $454^{\mathrm{b}}$ &, $436^{\mathrm{b}}$ &, $146^{\mathrm{b}}$ &, $000^{\mathrm{b}}$ &, $011^{\mathrm{b}}$ &, $380^{\mathrm{b}}$ \\
\hline \multirow{2}{*}{$\begin{array}{l}\text { Interv. } \\
\text { Conf. } \\
99 \%\end{array}$} & $\begin{array}{l}\text { Lim. } \\
\text { Inf. }\end{array}$ & 0 & ,026 & ,166 & ,001 & , 123 & 0,000 & ,184 & ,441 & ,423 & ,137 & 0,000 & ,008 &, 367 \\
\hline & $\begin{array}{l}\text { Lim. } \\
\text { Sup. }\end{array}$ & $\begin{array}{c}5 \mathrm{E}- \\
04\end{array}$ & ,034 & , 186 & ,003 & , 140 & 001 & ,204 & ,467 & 449, & ,155 & ,001 & ,014 & ,392 \\
\hline
\end{tabular}

Fonte: Os autores com base nos resultados da pesquisa

A partir dessas análises, foram elaboradas em Excel@ tabelas de comparação entre os setores para identificar quais setores mais se diferenciavam significativamente dos outros. A partir da formatação condicional do Excel®, valores de significância menores do que 0,002 (aproximação para o valor 0,0018 calculado anteriormente) foram coloridos em azul claro, ao passo que valores iguais a 0,002 foram coloridos em azul escuro. A

Tabela 6 e a Tabela 7apresentam dois setores que se destacaram nessa análise, o setor moveleiro e o setor de software, respectivamente.

Tabela 6 - Diferenças entre o setor Moveleiro e os outros setores

\begin{tabular}{|c|c|c|c|c|c|c|c|c|c|c|c|c|c|}
\hline Setor/Var & Ofer. & Plat. & Marca & Clien. & Sol. & Rel. & $\begin{array}{c}\text { Agreg. } \\
\text { valor }\end{array}$ & Proces. & Org. & $\begin{array}{c}\text { Cadeia } \\
\text { forn. }\end{array}$ & Pres. & Rede & $\begin{array}{c}\text { Amb. } \\
\text { Inov. }\end{array}$ \\
\hline Agroindústria & 0,059 & 0,481 & 0,007 & 0,000 & 0,108 & 0,032 & 0,961 & 0,848 & 0,185 & 0,706 & 0,470 & 0,059 & 0,301 \\
\hline
\end{tabular}




\begin{tabular}{|c|c|c|c|c|c|c|c|c|c|c|c|c|c|}
\hline Constr. Civil & 0,000 & 0,036 & 0,123 & 0,041 & 0,516 & 0,770 & 0,605 & 0,942 & 0,190 & 0,837 & 0,002 & 0,002 & 0,409 \\
\hline Metal Mec. & 0,000 & 0,055 & 0,344 & 0,286 & 0,750 & 0,881 & 0,394 & 0,488 & 0,505 & 0,011 & 0,004 & 0,007 & 0,527 \\
\hline Software & 0,076 & 0,561 & 0,000 & 0,000 & 0,000 & 0,017 & 0,000 & 0,000 & 0,000 & 0,247 & 0,703 & 0,000 & 0,000 \\
\hline Turismo & 0,000 & 0,062 & 0,004 & 0,001 & 0,000 & 0,001 & 0,012 & 0,137 & 0,630 & 0,931 & 0,068 & 0,000 & 0,080 \\
\hline Varejo & 0,033 & 0,200 & 0,115 & 0,002 & 0,000 & 0,244 & 0,360 & 0,653 & 0,086 & 0,365 & 0,003 & 0,000 & 0,000 \\
\hline Vestuário & 0,840 & 0,002 & 0,000 & 0,000 & 0,004 & 0,026 & 0,314 & 0,149 & 0,105 & 0,548 & 0,928 & 0,000 & 0,049 \\
\hline
\end{tabular}

Fonte: os autores com base nos resultados da pesquisa

Como é possível observar na

Tabela 6, o setor moveleiro possui um número reduzido de diferenças em relação aos outros setores. Esse setor possui muitas semelhanças com os setores da agroindústria, construção civil e metal mecânico, porém possui muitas diferenças em relação ao setor de software. Além disso, as dimensões que mais se diferenciam são a dimensão clientes e a dimensão redes. Retomando as médias de todos os setores apresentadas na Tabela 3, o setor moveleiro possui a menor média na dimensão redes e a segunda menor média na dimensão clientes.

Tabela 7 -Diferenças entre o setor de Software e os outros setores

\begin{tabular}{|c|l|l|l|l|l|l|l|l|l|l|l|l|l|}
\hline Setor/Var & Ofer. & Plat. & Marca & Clien. & Sol. & Rel. & $\begin{array}{c}\text { Agreg. } \\
\text { valor }\end{array}$ & Proces. & Org. & $\begin{array}{c}\text { Cadeia } \\
\text { forn. }\end{array}$ & Pres. & Rede & $\begin{array}{c}\text { Amb. } \\
\text { Inov. }\end{array}$ \\
\hline Agroindústria & 0,743 & 0,028 & 0,001 & 0,000 & 0,000 & 0,000 & 0,000 & 0,000 & 0,000 & 0,003 & 0,592 & 0,000 & 0,000 \\
\hline Constr. Civil & 0,000 & 0,002 & 0,002 & 0,000 & 0,000 & 0,003 & 0,000 & 0,000 & 0,000 & 0,404 & 0,000 & 0,000 & 0,000 \\
\hline Metal Mec. & 0,000 & 0,000 & 0,000 & 0,000 & 0,000 & 0,000 & 0,000 & 0,000 & 0,000 & 0,000 & 0,000 & 0,000 & 0,000 \\
\hline Moveleiro & 0,076 & 0,561 & 0,000 & 0,000 & 0,000 & 0,017 & 0,000 & 0,000 & 0,000 & 0,247 & 0,703 & 0,000 & 0,000 \\
\hline Turismo & 0,000 & 0,001 & 0,065 & 0,000 & 0,000 & 0,113 & 0,000 & 0,000 & 0,000 & 0,212 & 0,029 & 0,007 & 0,000 \\
\hline Varejo & 0,000 & 0,008 & 0,000 & 0,000 & 0,000 & 0,076 & 0,000 & 0,000 & 0,000 & 0,002 & 0,000 & 0,000 & 0,000 \\
\hline Vestuário & 0,068 & 0,000 & 0,617 & 0,204 & 0,000 & 0,844 & 0,000 & 0,000 & 0,000 & 0,325 & 0,410 & 0,004 & 0,000 \\
\hline
\end{tabular}

Fonte: os autores com base nos resultados da pesquisa

Em contrapartida, o setor de software (Tabela 7) se destaca por apresentar muitas diferenças em relação aos outros setores. Ainda assim, há algumas dimensões em que é semelhante aos outros setores, como na dimensão relacionamento e na dimensão cadeia de fornecimento. Também retomando as médias de todos os setores apresentadas na Tabela 3, o setor de software possui a segunda mais alta média em ambas as dimensões, contudo, outros setores também possuem médias elevadas, o que explica a semelhança entre os setores. Um resumo das diferenças pode ser visto na Tabela 8. 
Tabela 8 -Número de diferenças significativas por Setor

\begin{tabular}{|c|c|c|c|c|c|c|c|c|c|}
\hline \multicolumn{2}{|c|}{ Setor } & Agroind. & Constr. & Metal Mec. & Mov. & SW & Turismo & Varejo & Vest. \\
\hline \multirow{2}{*}{ p<0,002 } & Total & 46 & 36 & 54 & 35 & 72 & 47 & 46 & 54 \\
\cline { 2 - 11 } & $\%$ & $51 \%$ & $40 \%$ & $59 \%$ & $38 \%$ & $79 \%$ & $52 \%$ & $51 \%$ & $59 \%$ \\
\hline \multirow{2}{*}{ p<=0,002 } & Total & 48 & 38 & 56 & 36 & 74 & 50 & 48 & 56 \\
\cline { 2 - 11 } & $\%$ & $53 \%$ & $42 \%$ & $62 \%$ & $40 \%$ & $81 \%$ & $55 \%$ & $53 \%$ & $62 \%$ \\
\hline
\end{tabular}

Fonte: os autores com base nos resultados da pesquisa

A partir da Tabela 8é possível observar que mesmo os setores com pouca diferenciação, como o moveleiro e construção civil, possuem $40 \%$ de diferenças significativas em relação ao máximo possível (91), o que revela um alto índice de diferenciação entre os setores. Isso indica que cada setor possui especificidades em relação às diferentes dimensões da inovação e não seria recomendável comparar diretamente empresas de setores diferentes, conforme proposto por Oliveira et al. (2014).

\section{CONCLUSÕES}

A análise dos resultados obtidos permitiu concluir que, em linhas gerais, e observando a média das dimensões do Radar utilizadas por cada setor investigado, as empresas concentram seus investimentos em inovação nas dimensões plataforma e marca, identificadas como presentes em todos os setores analisados. Embora as empresas atuem em setores diversos e portanto, com características específicas, as inovações não são diversificadas no que se refere às dimensões em que ocorrem dentro do Radar da Inovação. Como consequência, há dimensões que estão sendo pouco exploradas por todos os setores investigados. Dimensões como cadeia de fornecedores, processos, agregação de valor e ambiência inovadora têm sido pouco exploradas e por essa razão, podem vir a constituir-se fonte de vantagem competitiva para as empresas que utilizam o Radar como instrumento para a construção de estratégias voltadas à inovação.

Contudo, embora as MPEs inovem em dimensões semelhantes, a análise estatística demonstrou diferenças significativas no que se refere à intensidade no uso da inovação entre os setores analisados. Assim, embora dois ou mais setores mostrem-se inovadores numa mesma direção, a intensidade da inovação difere de um setor para o outro. Foi observado que o setor moveleiro, por exemplo, é o menos inovador quando comparado aos demais setores, ao passo que o setor de software mostrou-se o mais inovador comparativamente.

Revista de Administração e Inovação, São Paulo, v. 12, n.4 p. 162-186, out./dez. 2015. 
Tal achado impede a comparação direta e intersetorial quando o tema é inovação. Assim, é a contribuição teórica desta pesquisa foi verificar que os setores diferem entre si quando analisados em termos de intensidade no uso da inovação, mas são semelhantes no que se refere às dimensões em que a inovação ocorre.

Em relação à metodologia, pode-se considerar ter sido adequada, pois os testes utilizados foram para dados não paramétricos, uma vez que não seguem uma distribuição normal. Futuros trabalhos poderiam complementar os resultados aqui apresentados ao incorporar os resultados da inovação e investigar a relação desses com as 13 dimensões do Radar da Inovação por meio de análises de correlação ou de regressão. Outros trabalhos também poderiam ampliar ainda mais a comparação entre diferentes setores, incorporando setores que não estavam presentes nesta pesquisa.

Em síntese, ao inovar em dimensões pouco exploradas, as empresas que utilizam o Radar da Inovação como ferramenta podem visualizar formas e estratégias para se diferenciarem em relação às demais empresas do seu setor, e essa diferenciação pode contribuir para o desenvolvimento de vantagens competitivas.

\section{REFERÊNCIAS}

Anthony, S. D. (2012). O livro de ouro da inovação: o guia definitivo para o sucesso organizacional e o crescimento pessoal. Rio de Janeiro: Elsevier.

Bachmann, D. (2009). Perfil do Grau de Inovação das MPEs do Paraná. Curitiba: SEBRAE/PR.

Bachmann, D. L.; Destefani, J. H. (2014). Metodologia para Estimar o Grau de Inovação nas MPE. Curitiba. Retirado

de:

<http://www.bachmann.com.br/website/documents/ArtigoGraudeInovacaonasMPE.pdf>.

Bachmann \& Associados (2009). Guia para a Inovação na Micro e Pequena Empresa: Dicas práticas para inovar na MPE. Curitiba.

Baregheh, A., Rowley, J., \& Sambrook, S. (2009). Towards a multidisciplinary definition of innovation. Management Decision, 47(8), p. 1323-1339.

Barney, J. B. (1996). Gaining and Sustaining Competitive Advantage, Reading - MA: AddisonWesley Publishing Company.

Capeleiro, M. C. C., \& Araújo, R.M. (2013). Análise sobre a dimensão oferta no contexto inovação dentro do setor de estruturas pré-moldadas na grande natal. REUNIR: Revista de Administração, Contabilidade e Sustentabilidade, 3(2), p. 39-65.

Carvalho, H. G. et al. (2015). Panorama das MPE do Paraná com base no Radar da inovação inicial do ciclo ALI PR 2012-2014. Espacios, 36(19), p. 21.

Revista de Administração e Inovação, São Paulo, v. 12, n.4 p. 162-186, out./dez. 2015. 
Carvalho, H. G., Reis, D. R., \& Cavalcante, M. B. (2011). Gestão da inovação. Curitiba: Aymará.

Chesbrough, H. (2007). Business model innovation: it's not just about technology anymore. Strategy \& Leadership, 35(6), p. 12-17.

Chesbrough, H. (2010). Business model innovation: opportunities and barriers. Long range planning, 43(2), p. 354-363.

Davila, T., Epstein, M. J. \& Shelton R. (2007). As regras da inovação. Porto Alegre: Bookman.

Denizot, A. E. R. (2014). As Pequenas Empresas de Tecnologia da Informação e Comunicação do Estado do Rio de Janeiro à Luz do Radar da Inovação: Identificação e Análise dos Principais Obstáculos para os Processos de Inovação. Sistemas \& Gestão, 9(3), p. 394-405.

Field, A. (2009). Descobrindo a Estatística usando SPSS. Porto Alegre: Artmed.

Freeman, C., \& Soete, L. (2009). Developing science, technology and innovation indicators: What we can learn from the past. Research policy, 38(4), p. 583-589.

IBM. (2014). How much memory can SPSS for Windows use? What are MXMEMORY and WORKSPACE and which procedures are affected? Recuperado de: <http://www01.ibm.com/support/docview.wss?uid=swg21479419>.

Ireland, R. D. \& Webb, J. W. (2007). Strategic entrepreneurship: Creating competitive advantage through streams of innovation. Business Horizons, 50(1), p. 49-59.

Hill, C. W. \& Deeds, D. L. (1996). The Importance of Industry Structure for the Determination of the Firm Profitability: A Neo-Austrian Perspective. Journal of Management Studies, 33(4), p.429-451 July.

Jacobson, R. (1992). The "Austrian" School of Strategy. Academy of Management Review, 17(4), p.782-807.

Johnson, M. W., Christensen, C. M., \& Kagermann, H. (2008). Reinventing your business model. Harvard Business Review, 86(12), p. 57-68.

Madrid-Guijarro, A., García-Pérez-De-Lema, D., \& Van Auken, H. An Investigation of Spanish SME Innovation during Different Economic Conditions. Journal of Small Business Management, 51(4), p. 578-601.

OCDE \& FIEP. (2005). Manual de Oslo. 3.ed. Retirado de: <http://www.mct.gov.br/upd_blob/0011/11696.pdf>.

OECD. (1981). The Measurement of Scientific and Technical Activities: "Frascati Manual". Paris: OECD. 
OECD. (1992). Oslo Manual: The Measurement of Scientific and Technological Activities: Proposed Guidelines for Collecting and Interpreting Technological Innovation Data. Paris: OECD.

Oliveira, M. R. G. et al. (2011). Grau de Inovação Setorial: Uma abordagem a partir do Radar de Inovação. In: Encontro Nacional de Engenharia de Produção, 31.. Anais do.... Belo Horizonte, UNESP, p. 1-13.

Oliveira, M. R. G. et al. (2014). Mensurando a inovação por meio do grau de inovação setorial e do característico setorial de inovação. RAI - Revista de Administração e Inovação, 11(1), p. 115-137.

Porter, M. E. (1996). What is strategy? Harvard Business Review, Boston, 74(6), p. 61-78, Nov/Dec.

Sawhney, M., Wolcott, R. C., \& Arroniz, I. (2006). The 12 Different Ways for Companies to Innovate. MIT Sloan Management Review, Spring, p. 75-81.

Santos, D.F.L., Basso L., \& Kimura, H. (2010). A influência da inovação no desempenho financeiro das empresas. Anais do Simpoi, FGV-SP.

Sbragia, R., Andreassi, T., Campanário, M. A., \& Stal, E. (2006). Inovação: como vencer este desafio empresarial. São Paulo: Clio Editora.

SEBRAE. (2014). Agentes Locais de Inovação. Retirado de: <http://www.sebrae.com.br/sites/PortalSebrae/Programas/Agentes-Locais-deInova\%C3\%A7\%C3\%A3o:-receba-o-Sebrae-na-sua-empresa .

SEBRAE-PR. (2014). Agentes Locais de Inovação. Recuperado de: <http://app.pr.sebrae.com.br/ali/Conteudo.do?codConteudo=2083\&codMenuAtivo=709>.

Silva Néto, A. T., \& Teixeira, R. M. (2014). Inovação de Micro e Pequenas Empresas: Mensuração do Grau de Inovação de Empresas Participantes do Projeto Agentes Locais de Inovação. BBR-Brazilian Business Review, 11(4), p. 1-29.

Silva Néto, A. T., \& Teixeira, R. M. (2011). Mensuração do grau de inovação de micro e pequenas empresas: estudo em empresas da cadeia têxtil-confecção em Sergipe. RAI: Revista de Administração e Inovação, 8(3), p. 205-229.

Teece, D. J. (2010). Business models, business strategy and innovation. Long Range Planning, 43(2), p. 172-194.

Tidd, J., Bessant, J. R., \& Pavitt, K. (2008). Gestão da inovação. 3. ed. Porto Alegre: Bookman.

Winter, S. G. (1987). Knowledge and Competence as Strategic Assets, in D. Teece (ed.), The Competitive Challenge: Strategies for Industrial Innovation and Renewal, Cambridge, MA: Ballinger, p.159-184. 
ANEXO - RESUMO DAS QUESTÕES DO RADAR DA INOVAÇÃO

\begin{tabular}{|c|c|c|}
\hline Dimensão & Q & Questões (considerando os últimos três anos) \\
\hline \multirow{6}{*}{ Oferta } & 1 & Atuação em novos mercados. \\
\hline & 2 & Lançamento de novos produtos. \\
\hline & 3 & Remoção de produtos sem sucesso do mercado. \\
\hline & 4 & Mudanças nas características de produtos por razões ambientais. \\
\hline & 5 & Mudanças significativas no design de produtos. \\
\hline & 6 & Adoção de inovações tecnológicas. \\
\hline \multirow{2}{*}{ Plataforma } & 7 & Recursos utilizados para famílias de produtos. \\
\hline & 8 & Mesmo produto oferecido em diferentes versões para novos mercados. \\
\hline \multirow{2}{*}{ Marca } & 9 & Registro de marcas. \\
\hline & 10 & Utilização da marca em diferentes meios. \\
\hline \multirow{4}{*}{ Clientes } & 11 & Identificação de novas necessidades dos clientes. \\
\hline & 12 & Identificação de novos mercados. \\
\hline & 13 & $\begin{array}{c}\text { Utilização de manifestações de clientes (sugestões, reclamações) para desenvolver } \\
\text { novos produtos. }\end{array}$ \\
\hline & 14 & Lançamento de produtos decorrentes de necessidades de clientes. \\
\hline \multirow{2}{*}{ Soluções } & 15 & Oferecer novas soluções complementares aos clientes. \\
\hline & 16 & Oferecer novas soluções com base na integração de recursos. \\
\hline \multirow{2}{*}{ Relacionamento } & 17 & Aperfeiçoamento no relacionamento com clientes por meio de facilidades ou recursos. \\
\hline & 18 & Utilização de recursos informáticos para se relacionar com clientes. \\
\hline \multirow{2}{*}{$\begin{array}{c}\text { Agregação de } \\
\text { Valor }\end{array}$} & 19 & Utilização dos recursos existentes para geração de novas receitas. \\
\hline & 20 & Utilização dos relacionamentos com parceiros para geração de novas receitas. \\
\hline \multirow{6}{*}{ Processos } & 21 & Aperfeiçoamento de processos. \\
\hline & 22 & Adoção de práticas de gestão. \\
\hline & 23 & Adoção de certificações. \\
\hline & 24 & Adoção de softwares de gestão. \\
\hline & 25 & Aperfeiçoamento de processos em relação a aspectos ambientais. \\
\hline & 26 & Redução ou utilização de resíduos. \\
\hline \multirow{4}{*}{ Organização } & 27 & Reorganização ou utilização de novas abordagens para as atividades. \\
\hline & 28 & Realização de novas parcerias. \\
\hline & 29 & Adoção de novas formas de trocar informações e ideias com clientes e fornecedores. \\
\hline & 30 & Mudanças na estratégia competitiva. \\
\hline $\begin{array}{c}\text { Cadeia de } \\
\text { Fornecimento }\end{array}$ & 31 & Aperfeiçoamentos no transporte, distribuição e estoques. \\
\hline \multirow{2}{*}{ Presença } & 32 & Criação de novos pontos ou canais de vendas. \\
\hline & 33 & Estabelecimento de novas relações com distribuidores e representantes comerciais. \\
\hline Rede & 34 & Adoção de novas formas de comunicação com os clientes. \\
\hline \multirow{8}{*}{$\begin{array}{l}\text { Ambiência } \\
\text { Inovadora }\end{array}$} & 35 & Utilização de consultorias ou apoio de instituições como universidades SEBRAE etc. \\
\hline & 36 & Participação em eventos para busca de informações. \\
\hline & 37 & Busca de conhecimentos junto a fornecedores e clientes. \\
\hline & 38 & Investimentos em aquisição de tecnologias, know-how, técnicas etc. \\
\hline & 39 & Investimento em propriedade intelectual. \\
\hline & 40 & Execução de projetos para desenvolver ou introduzir inovações tecnológicas. \\
\hline & 41 & Utilização de programas governamentais de apoio para atividades inovadoras. \\
\hline & 42 & Utilização de sistemas de gestão de ideias. \\
\hline
\end{tabular}

Fonte: os autores com base em Bachmann (2009,) Bachmann e Destefani (2008) e Bachmann \& Associados (2009). 


\title{
INNOVATION RADAR AS A TOOL FOR COMPETITIVE ADVANTAGE OF REACH FOR MICRO AND SMALL ENTERPRISES
}

\begin{abstract}
Organizations in general have pursued innovation as a means of gaining competitive advantage. In the context of micro and small enterprises (MSEs), this practice has been supported by the Brazilian Service of Support for Micro and Small Enterprises (Sebrae) through Local Innovation Agents (ALI) program, which aims to strengthen the practice of innovation by identifying opportunities to innovate. The main tool used in this work is the Innovation Radar, which is based on the original work of Sawhney, Wolcott and Arroniz (2006). This study aimed to achieve two main objectives: i) to analyze how MSEs can use the radar as a tool for building strategies for innovation; ii) comparatively analyze the sectors participating in the sample with regard to the extent to which innovation occurs and the importance of innovation for each sector analyzed. The study sample was composed of 1139 micro and small businesses that joined the ALI program in 2012, in the State of Paraná. The data were analyzed by statistical tests such as the Kruskal-Wallis, Mann-Whitney and others. The results showed that the MSEs, innovate through similar dimensions of the Radar, even if they belong to different sectors. However, the difference between the sectors is analyzed in innovation intensity, which was more robust in the software sector and weaker in the furniture sector. It was also found that many dimensions of innovation Radar were little explored, which shows great potential for gaining competitive advantage.
\end{abstract}

Keywords: Innovation; Innovation Radar; Dimensions of Innovation; Agents Local Innovation Program (ALI); Innovation in Micro and Small Enterprises (MSEs).

Data do recebimento do artigo: 12/01/2015

Data do aceite de publicação: 20/11/2015

Revista de Administração e Inovação, São Paulo, v. 12, n.4 p. 162-186, out./dez. 2015. 